\title{
Forecasting Crime and Understanding its Causes. Applying Risk Terrain Modeling Worldwide
}

\author{
Leslie W. Kennedy ${ }^{1} \cdot$ Marco Dugato $^{2}$ (i)
}

Published online: 15 November 2018

(C) Springer Nature B.V. 2018

We are pleased to introduce a special issue on risk terrain modeling (RTM) with expert contributions from around the world. The intent of this issue is to highlight the advances that have been made in the use of the RTM approach and to provide an opportunity to test its applicability in many different settings and geographies. The issue is also intended to provide insights for scholars who are interested in exploring the theoretical and methodological applications of RTM in relation to the unifying themes of environmental criminology and the spatial aspects of crime. Our intention was to address the different aspects of the inquiry inspired by the development of RTM, including theoretical tests, empirical verification, and practical applications. In addressing their research questions, authors were encouraged to present the rationale behind RTM, looking at contextual factors for making crime forecasts that are more useful for guiding interventions and more capable in identifying future possible crime concentrations. We added to this a planned solicitation of papers from researchers working in different countries, faced with diverse data issues, law enforcement practices, and analytical challenges. Indeed, the contributions of this special issue cover four continents, including North America (Andresen and Hodgkinson 2018; Piza et al. 2018), South America (Giménez-Santana et al. 2018a), Asia (Ohyama and Amemiya 2018), Northern Europe (Gerell 2018), Southern Europe (Dugato et al. 2018; Giménez-Santana et al. 2018b), and the transcontinental city of Istanbul connecting Southern Europe and the Middle-East (Onat and Gul 2018).

\section{RTM and Environmental Criminology}

According to Brantingham and Jeffery, in the criminological research by early positivists, "Distance, location, target distribution were all irrelevant to the object of study. [...] Directly

Marco Dugato

marco.dugato@unicatt.it

Leslie W. Kennedy

les.kennedy@ rutgers.edu

1 School of Criminal Justice, Rutgers University, Newark, NJ, USA

2 Università Cattolica del Sacro Cuore - Transcrime, Milan, Italy 
spatial explanations of crimes were a priori excluded from the consideration of the theoretical structure that criminologists used to define their problem and interpret their data. The result was a major dysfunction between data and theory, a collapse into the problems of the ecological fallacy, and the sort of sterile exploration of spatial data about crime that occurred in the 1950s and 1960s. Criminologists became guilty of ignoring or avoiding crime data which failed to fit the theoretical structure" (Brantingham and Jeffery 1981, pp. 234-235). Responding to this critique, there was an increased emphasis on opportunities, considered a function of the distribution of physical and social criminogenic conditions across the landscape (Cohen et al. 1981). The opportunities approach became central to environmental criminology and governed many of the emerging strategies by police to document crime occurrence, using mapping to display and eventually forecast the distributions of crime.

Opportunities derive from environmental features that support criminality. However, if we fail to make the connection to individual decision-making, these opportunities are hard to anticipate. Further, this approach does not address the main issue that environmental criminology sought to overcome, that is, the persistence of crime in certain locations. Saying that crime opportunities concentrate does not shed light on the reasons why this occurs, beyond the fact that it happens close to where other crime has happened. Also, these explanations reinforce the views of the police that crime is person based, committed by "bad" people, and environmental factors are outside of the scope of policing in responding to crime. Police have persisted in their resistance to location-based explanations and are supported in this resistance by research that downplays the important role of environment in affecting behavior.

This debate is made more complicated by the fact that different groups are governed by their own narratives, a point made clear by Brantingham and Jeffery (1981). The underlying reasons for crime are highly disputed and there can be quite different arguments for why it occurs. Even in the small research area of environmental criminology, differences are quite striking in terms of both methods and theories used to explain crime. However, it is important to note that a common element in this approach is spatial influence, referring to the way in which some landscape features affect peoples' behaviors in the surrounding places (Caplan 2011). In its limited form, spatial influence can be considered as affecting the concentration of incidents, leading to a focus on the exposure of individuals to opportunities for crime and the resulting outcomes based on choices that offenders and victims make in managing their activities. In its more expansive application, spatial influence can be examined by adding a consideration of vulnerability to risky elements in environments. This approach considers risk as part of an analysis that forecasts environmental and social impacts on crime, rather than looking at these effects after the fact (Caplan and Kennedy 2016).

Routine activities theory (RAT) is an approach that is based on lifestyles and patterns of behavior that are generally not considered spatially. Rather, they float above the urban environment, only partially influenced by the geographic reality that underpins them. If there is a connection made, it is generally in the form of boundary effects where routine activities are considered within an area but not necessarily influenced by specifics of that area. It is true that specific aspects of the RAT approach have been considered in micro places, for example, the differential role that guardians play in certain locations (Andresen 2014). Also, the importance of victim experiences in explaining near repeats has an impact on the ways in which analysts have interpreted the movement of crime in certain locations (an important factor for Brantingham and Brantingham 1981). However, the routine activities themselves are not considered in this micro way and so prescriptions about prevention deriving from these are hard to make, except if we consider opportunities as a manifestation of the routine activities 
themselves. In other words, the routine activities are proxies for the opportunities that emerge in locations and can be considered as factors that promote crime. This brings the analysis to the micro level and the prevention strategies through situational actions more directly connected to individual behavior. However, while this seems to make sense conceptually, how do we actually measure these effects and determine the efficacy of these approaches without getting muddled in the process? And to the original point raised above, how do we translate these into spatial factors that help us understand the distribution and persistence of these effects?

RTM is a response to these issues. RTM is a step-by-step process that refers to three key elements: 1) standardizing disparate datasets to a common geography, 2) diagnosing spatial risk factors, and 3) articulating spatial vulnerabilities. The first stage involves a cartographic process of operationalizing qualities of a landscape to geographic maps. These map layers represent the spatial influences of environmental factors across places. The second step involves a statistical process that identifies and weights factors that geographically relate to crime incidents. The third stage comprises a cartographic process whereby the spatial influences of these environmental factors are combined to communicate information about spatial contexts for crime. Although some steps entailed by this program can be automated, RTM is not itself a software or an algorithm, rather a methodological approach that suggests an analytical procedure, leaving a wide range of flexibility about the specific techniques or methods that can be adopted. RTM offers a valid way to articulate vulnerable places at the micro-level. Risk scores of places derived from this analysis do not suggest the inevitability of crime. Instead, they point to locations where the likelihood of criminal behavior will be high (Kennedy et al. 2016). Knowing where and why the underlying problems emerge and persist over time provide opportunities to align prevention services in the areas that need them most.

\section{The Theory of Risky Places}

Given the current thinking about crime vulnerability based on concentration and spatial influence of features and events, RTM offers an analytical strategy to model risky places that combines the conceptual insights of crime emergence and persistence, advances in geo-spatial analytical techniques, and access to micro-level data. This approach follows the tenets that define the development of middle-range theories, as outlined by Merton. In specific terms, he suggested that "...middle range theories consist of limited sets of assumptions from which specific hypotheses are logically derived and confirmed by empirical investigation" (1967, p. 68). To meet these criteria, Kennedy and Caplan (2013) proposed the Theory of Risky Places. This theory addresses the ways in which spatial influences of risk features impact on behavior outcomes, such as crime. This framework supports three propositions:

1) All places are risky, but because of the spatial influence of criminogenic features, some places are riskier than others;

2) Crime emerges at places when there is high vulnerability based on the combined spatial influences of criminogenic features at said places; and

3) The overall effect of risky places on crime is a function of differential vulnerability and exposure throughout the landscape.

These propositions provide a basis for analyzing the processes whereby crime emerges, persists, or disappears. It operationalizes the criminogenic factors for crime and applies a 
series of tests to demonstrate how this modeling can be consistent with the assumptions about crime concentration and spatial influence.

\section{This Special Issue}

This theory and its propositions provide the overall framework for the papers that are presented in this special issue. Merton emphasized the importance of middle-range theories in cutting across the distinction between micro-sociological problems and macro-sociological problems. This approach emphasizes the importance of adding new knowledge and, relevant to the papers included here, extending the empirical tests of the relationships under study across settings, both cultural and geographical. The intent here was not only to determine if the RTM approach would work in different environments, but also to assess how the theoretical assumptions made in the theory of risky places stood up in cross-national inquiry.

The first four papers foster the current debate about how environmental and contextual factors could or should be analyzed to obtain forecasts that are more accurate and to orient interventions that are more effective. In particular, Gerell (2018) focuses on understanding the association between bus stops and violent crime in the city of Malmö, Sweden. His paper suggests that flows of people at risk are a necessary element to be considered allowing to distinguish the absolute crime risk from the relative victimization risk and, consequently, affecting both the results of the forecasting procedures and the resulting policy interventions. Andresen and Hodgkinson (2018) investigate residential burglaries in the city of Vancouver, Canada. Their findings advocate that social structural factors should also be considered when predicting risk, although particular attention should be given to the specific variable selection according to the type of crime under study. Also, Dugato et al. (2018) analyzed residential burglaries focusing on the Italian city of Milan. This paper isolates the risk factors related to the target characteristics from the ones connected to the contextual environment for defining the overall vulnerability of an area. The aim is to prevent incorrect indications of causality between crime and risk factors that may lead to the wrong prediction or ineffective interventions. Finally, Giménez-Santana and colleagues (2018a) use RTM to forecast the occurrence of some violent and appropriative crimes in the city of Bogotà, Colombia. As in the previous contributions, this paper proposes the introduction of contextual social data among the risk factors thanks to the availability of peculiar micro level information (i.e., "strata"). Their findings also support the use of RTM as a complementary tool for more traditional hot spot analysis. It is relevant to notice how all four studies, despite the different methodologies and context of applications, stress the importance of including socio-demographic data, at meso- or micro-level, in the RTM analysis as a further way to control and better understand the relationship between crime and environmental features.

The special issue continues with two other applications of RTM to forecast innovative crime issues. In particular, Onat and Gul (2018) propose a forecasting method for terrorist attacks in Istanbul, Turkey. The paper suggests that risk factors and the consequent areal vulnerabilities are linked to the different groups' ideologies. Giménez-Santana and colleagues (2018b) focus on traffic accidents in the Province of Cadiz, Spain assessing how the presence of risk facilities increases the likelihood of a road crash. Both these studies prove that the forecasting method based on contextual risk assessment suggested by the RTM approach can also be successfully applied to non-traditional security issues, such as terrorism or road safety. 
The last two papers of this special issue introduce some reflections about the challenges faced by researchers and agencies in applying evidence-based crime forecasting approaches. Specifically, the study by Ohyama and Amemiya (2018) focuses on the Japanese situation where very low crime numbers seriously jeopardize the use of forecasting methods based on previous crime data. Comparing the performances of several crime forecasting techniques applied to thefts from vehicles in Fukuoka, Japan this paper proves that RTM outperforms other methods, thus supporting a predicting approach based on environmental factors. Finally, the paper by Piza et al. (2018) presents a large project aiming at spreading the use of RTM in the everyday activities of seven agencies across the United States. The study focuses on and discusses the strategy used for implementing the project and the challenges encountered during the interaction between researchers and police practitioners.

In summary, this special issue addresses the future of RTM highlighting how it should not be seen as a tool, an algorithm or a statistical method, but as a comprehensive approach to crime forecasting based on contextual risk evaluation. The eight papers explore spatial theory and apply several methodologies relying on more or less advanced or automatized techniques; analyzing a wide array of diverse crime issues; and focusing on various geographical, social, and economic settings. Despite this variety, RTM is proven as a solid approach for risk analysis, assessment, and forecast. Additionally, this variety confirms the flexibility of RTM in responding to specific challenges posed by different crimes and settings allowing researchers and practitioners to select the most suitable strategy considering their knowledge, aims, and data.

Going forward, RTM researchers are exploring new applications of the approach, including simulation modeling (Garnier et al. 2018) and implementation in risk-based policing (Kennedy et al. 2018). The future holds new challenges for spatial analysis of crime and we believe that this special issue has made a significant contribution to this emerging field of inquiry.

Publisher's Note Springer Nature remains neutral with regard to jurisdictional claims in published maps and institutional affiliations.

\section{References}

Andresen, M. A. (2014). Environmental criminology: Evolution, theory, and practice (1 edizione). London: Routledge.

Andresen, M. A., \& Hodgkinson, T. (2018). Predicting property crime risk: an application of risk terrain modeling in Vancouver, Canada. European Journal on Criminal Policy and Research, 373-392. https://doi.org/10.1007/s10610-018-9386-1.

Brantingham, P. J., \& Jeffery, C. R. (1981). Afterword: Crime, space and criminological theory. In P. L. Brantingham \& P. J. Brantingham (Eds.), Environmental criminology (pp. 227-238). Beverly Hills: Sage. Retrieved from https://trove.nla.gov.au/version/31356408.

Brantingham, P. L., \& Brantingham, P. J. (Eds.). (1981). Environmental criminology. Beverly Hills: Sage. Retrieved from https://trove.nla.gov.au/version/31356408.

Caplan, J. M. (2011). Mapping the spatial influence of crime correlates: A comparison of operationalization schemes and implications for crime analysis and criminal justice practice. Cityscape, 57-83.

Caplan, J. M., \& Kennedy, L. W. (2016). Risk terrain modeling: crime prediction and risk reduction. Berkeley: Univeristy of California Press. Retrieved from http://search.ebscohost.com/login.aspx?direct=true\&scope= site $\& \mathrm{db}=$ nlebk\&db=nlabk\&AN $=1218464$

Cohen, L. E., Kluegel, J. R., \& Land, K. C. (1981). Social inequality and predatory criminal victimization: an exposition and test of a formal theory. American Sociological Review, 46(5), 505-524. https://doi. org/10.2307/2094935. 
Dugato, M., Favarin, S., \& Bosisio, A. (2018). Isolating target and neighbourhood vulnerabilities in crime forecasting. European Journal on Criminal Policy and Research, 393-415. https://doi.org/10.1007 /s10610-018-9385-2.

Garnier, S., Caplan, J. M., \& Kennedy, L. W. (2018). Predicting dynamical crime distribution from environmental and social influences. Frontiers in Applied Mathematics and Statistics, 4. https://doi.org/10.3389 /fams.2018.00013.

Gerell, M. (2018). Bus stops and violence, are risky places really risky? European Journal on Criminal Policy and Research, 351-371. https://doi.org/10.1007/s10610-018-9382-5.

Giménez-Santana, A., Caplan, J. M., \& Drawve, G. (2018a). Risk terrain modeling and socio-economic stratification: identifying risky places for violent crime victimization in Bogotá, Colombia. European Journal on Criminal Policy and Research, 417-431. https://doi.org/10.1007/s10610-018-9374-5.

Giménez-Santana, A., Medina-Sarmiento, J. E., \& Miró-Llinares, F. (2018b). Risk terrain modeling for road safety: Identifying crash-related environmental factors in the province of Cádiz, Spain. European Journal on Criminal Policy and Research, 451-467. https://doi.org/10.1007/s10610-018-9398-x.

Kennedy, L. W., \& Caplan, J. M. (2013). A theory of risk places. Newark: Rutgers Center on Public Security.

Kennedy, L. W., Caplan, J. M., \& Piza, E. L. (2018). Risk-based policing: Evidence-based crime prevention with big data and spatial analytics. Berkeley: University of California Press. Retrieved from https://www.ucpress. edu/book/9780520295636/risk-based-policing.

Kennedy, L. W., Caplan, J. M., Piza, E. L., \& Buccine-Schraeder, H. (2016). Vulnerability and exposure to crime: applying risk terrain modeling to the study of assault in Chicago. Applied Spatial Analysis and Policy, 9(4), 529-548. https://doi.org/10.1007/s12061-015-9165-z.

Merton, R. K. (1967). On theoretical sociology: Five essays, old and new. New York: Free Press.

Ohyama, T., \& Amemiya, M. (2018). Applying crime prediction techniques to Japan: a comparison between risk terrain modeling and other methods. European Journal on Criminal Policy and Research, 469-487. https://doi.org/10.1007/s10610-018-9378-1.

Onat, I., \& Gul, Z. (2018). Terrorism risk forecasting by ideology. European Journal on Criminal Policy and Research, 433-449. https://doi.org/10.1007/s10610-017-9368-8.

Piza, E. L., Kennedy, L. W., \& Caplan, J. M. (2018). Facilitators and impediments to designing, implementing, and evaluating risk-based policing strategies using risk terrain modeling: insights from a multi-city evaluation in the United States. European Journal on Criminal Policy and Research, 489-513. https://doi. org/10.1007/s10610-017-9367-9. 